\title{
Prenatal stress induces intrauterine growth restriction and programmes glucose intolerance and feeding behaviour disturbances in the aged rat
}

\author{
J Lesage, F Del-Favero ${ }^{1}$, M Leonhardt, H Louvart ${ }^{1}$, S Maccari ${ }^{1}$, \\ D Vieau and M Darnaudery ${ }^{1}$
}

Laboratoire de Neuroendocrinologie du Développement, UPRES-EA 2701, Université de Lille 1, 59655 Villeneuve d'Ascq, France

${ }^{1}$ Laboratoire du Stress Périnatal, JE 2365, Université de Lille 1, 59655 Villeneuve d'Ascq, France

(Requests for offprints should be addressed to J Lesage, Laboratoire de Neuroendocrinologie du Développement, UPRES-EA 2701, Université de Lille 1, Bât. SN4, 59655 Villeneuve d'Ascq, France; Email: jean.lesage@univ-lille1.fr)

\begin{abstract}
There is growing evidence that prenatal adversities could be implicated in foetal programming of adult chronic diseases. Since maternal stress is known to disturb the foetal glucocorticoid environment, we examined the consequences of prenatal stress on foetal growth, on glucoseinsulin metabolism and on feeding behaviour in the aged male rat. In foetuses at term, maternal stress reduced body, adrenal and pancreas weight as well as plasma corticosterone and glucose levels. In aged male rats $(24$ months of

age), prenatal stress induced hyperglycaemia and glucose intolerance and decreased basal leptin levels. Moreover, after a fasting period, they showed an increased food intake. These data suggest that maternal stress induces a long-lasting disturbance in feeding behaviour and dysfunctions related to type 2 diabetes mellitus. This programming could be linked to the early restricted foetal growth and to the adverse glucocorticoid environment in utero.

Journal of Endocrinology (2004) 181, 291-296
\end{abstract}

\section{Introduction}

In humans, an inverse relationship between birth weight and adult ischaemic heart disease has been described, suggesting the role of prenatal 'programming' as a determinant of adult diseases (Barker \& Osmond 1986). This suggests that environmental influences acting on foetal life are reflected in altered birth size/phenotype and permanently affect structure and metabolism, thereby leading to a greater risk of developing coronary heart disease, hypertension, insulin-resistance syndromes and osteoporosis (Barker 1998, Nathanielsz \& Thornburg 2003). However, while increasing epidemiological evidence supports the role of early developmental growth patterns in the development of specific adult diseases, the determinant of the foetal growth restriction remains unclear. Maternal hormonal and nutritional status may be particularly important (Holness et al. 2000, Lesage et al. 2002). In this view, in humans and in rodents prenatal glucocorticoid overexposure induced by hormonal treatment or by maternal stress during gestation has been proposed to programme an adverse adult cardiovascular, metabolic, neuroendocrine and behavioural phenotype (Seckl 2001).

In rats, prenatal stress (PS) is known to disturb the foetal environment and to programme permanently neuroendocrine and behavioural responses in adult offspring (Maccari et al. 2003). For example, PS increased stress-induced adrenocorticotrophin (ACTH) and corticosterone (CORT) secretion and decreased binding capacity of hippocampal glucocorticoid receptors (GRs) (Koehl et al. 1999). These hypothalamo-pituitary-adrenal (HPA) axis dysfunctions have been suggested to be mediated by maternal glucocorticoids during pregnancy. Indeed, adrenalectomy of pregnant dams suppressed the effects of maternal stress on the HPA axis of the offspring (Barbazanges et al. 1996). Even if PS constitutes a model of glucocorticoid overexposure in utero, few studies have explored its long-lasting consequences on metabolic parameters. It was reported that in young adult animals PS increased basal glycaemia and reduced both body weight and food intake (Vallée et al. 1996). However, although the vulnerability to develop certain metabolic disorders such as type 2 diabetes mellitus strongly increases with ageing (Holness et al. 2000), metabolic alterations in aged PS rats have never been investigated. The aim of the present study was to evaluate if PS induces an in utero growth restriction and increases the vulnerability to develop metabolic disorders with ageing such as altered glucose-insulin metabolism and disturbed feeding behaviour. 


\section{Materials and Methods}

\section{Subjects}

Female Sprague-Dawley rats $(250 \mathrm{~g})$ were mated with a male for one night. The next day was considered as day 0 of pregnancy if spermatozoa were found in the vaginal smears. Pregnant females were then transferred to individual cages. During the last week of pregnancy (from embryonic day E14 to E21), pregnant females in the stress group $(n=10)$ were placed for $45 \mathrm{~min}$ in a transparent plastic cylinder in a lighted environment three times per day $(0900,1200$ and $1700 \mathrm{~h})$. Control females $(n=10)$ were left undisturbed. For studies in foetuses at term (E21), the maternal stress procedure was continued until E20. This stress procedure was previously described by Maccari et al. (1995). After weaning, offspring were housed in groups of four animals and left undisturbed for 23 months. Then, aged male rats were individually housed for 1 month before the beginning of experiments. All rats were maintained on a $12 \mathrm{~h}$ light: $12 \mathrm{~h}$ darkness cycle (lights on 0800-2000 h), with free access to food and water. Manipulation of the animals was performed following the principles of laboratory animal care published by the French Ethical Committee and the rules of the European Union Normative (86/609/EEC).

\section{Plasma and tissue collections}

On day 21 of gestation, pregnant females at term $(n=6$ females/group) were killed rapidly by decapitation between 1000 and 1200 h. Each litter usually contained 8-12 foetuses, which were collected by caesarean section, rapidly weighed and killed by decapitation.

Trunk blood samples of foetuses were collected after decapitation in tubes pre-rinsed with EDTA. Blood glucose was measured using a glucometer (One Touch II; Lifescan, Roissy, France). Body length was measured in foetuses and the adrenals and the pancreas were removed and weighed.

For aged male rats (24 months old), a maximum of two males from the same litter were used. After food intake measurements and oral glucose tolerance tests (OGTTs), rats were killed at rest by decapitation between 1000 and $1200 \mathrm{~h}$. Trunk blood was collected and blood glucose was measured.

Adrenals, pancreas and the perirenal and perigonadal fat pads were removed and weighed. All blood samples were centrifuged at $3200 \mathrm{~g}$ for $10 \mathrm{~min}$ at $4{ }^{\circ} \mathrm{C}$ and plasma samples were kept at $-30^{\circ} \mathrm{C}$ prior to $\mathrm{CORT}$ and leptin assays.

\section{OGTTS}

OGTTs were performed on eight or nine animals from both groups at 24 months of age after a $16 \mathrm{~h}$ fasting.
Animals were given $2 \mathrm{~g}$ glucose $/ \mathrm{kg}$ body weight with an oral cannula. Blood samples were collected from the tail vein $5 \mathrm{~min}$ before (time 0) and 60 and $120 \mathrm{~min}$ after glucose load. Blood glucose was measured and plasma aliquots were kept at $-30{ }^{\circ} \mathrm{C}$ until assayed for insulin.

\section{Food intake measurement}

Basal feeding behaviour was evaluated by measuring consumption of food in the home cages of the animals for a $24 \mathrm{~h}$ period. Cumulative food intake was also determined for 1, 2, 3 and $24 \mathrm{~h}$ periods after $24 \mathrm{~h}$ of fasting. Food consumption was determined by placing $150 \mathrm{~g}$ of chow in the home cage and weighing the residual food at indicated intervals.

\section{RIAs}

Plasma CORT levels were measured with an ${ }^{125}$ I RIA kit (ICN Biomedicals, Irvine, CA, USA) using a highly specific CORT antibody and a detection threshold of $0 \cdot 1 \mu \mathrm{g} / 100 \mathrm{ml}$.

Plasma insulin levels were measured using monoiodinated ${ }^{125}$ I-labelled porcine insulin (Sorin Biomedica, Sallugia, Italy) as a tracer, guinea pig anti-insulin antibody kindly provided by Dr Van Schravendijk (Brussels, Belgium) and purified rat insulin (Novo Nordisk, Boulogne, France) as standard. Charcoal was used to separate free from bound hormone. The sensitivity of the assay was $0.25 \mathrm{ng} / \mathrm{ml}$.

Plasma leptin concentration was measured using a rat/mouse leptin RIA kit (LEP-R61; Mediagnost, Tuebingen, Germany). Standards and ${ }^{125}$ I-labelled tracer were prepared from recombinant mouse leptin. No crossreactivity was found with insulin and insulin-like growth factor-I. Sensitivity was $6 \mathrm{pg} / \mathrm{ml}$ in undiluted plasma samples.

\section{Statistical analysis}

All data are presented as means \pm S.E.M. Morphometric and biological parameter comparisons between control and PS rats were performed using independent Student's $t$-tests. One-way ANOVA followed by a NewmanKeuls (NK) post-hoc test was used to compare groups for parameters with repeated measures (OGTT test and food intake measurement). $P<0 \cdot 05$ was considered significant.

\section{Results}

Effect of maternal stress on physiological parameters of foetuses at term

Foetuses from stressed mothers showed reduced body weight both in males $(P<0 \cdot 001)$ and in females $(P<0 \cdot 01)$, 
Table 1 Effects of maternal stress during the last week of gestation on morphometric and biological parameters of foetuses at term (day 21 of gestation). Data are means \pm S.E.M. $(n=29$ male foetuses/group and $n=31-39$ female foetuses/group for body weight values; $n=13-20$ male foetuses/group for others parameters)

\begin{tabular}{|c|c|c|}
\hline & Control & PS \\
\hline \multicolumn{3}{|l|}{ Body weight (g) } \\
\hline Males foetuses & $6 \cdot 09 \pm 0.09$ & $5 \cdot 34 \pm 0 \cdot 10^{* * *}$ \\
\hline Female foetuses & $5.85 \pm 0.09$ & $5 \cdot 46 \pm 0 \cdot 08^{* *}$ \\
\hline Body length $(\mathrm{cm})$ & $4 \cdot 89 \pm 0 \cdot 04$ & $4 \cdot 84 \pm 0 \cdot 05$ \\
\hline Adrenals (mg) & $3 \cdot 33 \pm 0 \cdot 28$ & $2 \cdot 20 \pm 0 \cdot 25^{* *}$ \\
\hline Pancreas (mg) & $30 \cdot 78 \pm 0 \cdot 88$ & $25 \cdot 49 \pm 0 \cdot 86^{\star * *}$ \\
\hline Plasma glucose $(\mathrm{mg} / \mathrm{dl})$ & $77 \cdot 10 \pm 4 \cdot 44$ & $60 \cdot 76 \pm 4 \cdot 24^{*}$ \\
\hline Plasma CORT $(\mu \mathrm{g} / \mathrm{dl})$ & $7 \cdot 07 \pm 0 \cdot 76$ & $2 \cdot 40 \pm 0 \cdot 35^{\star \star *}$ \\
\hline Plasma leptin (ng/ml) & $2 \cdot 71 \pm 0 \cdot 29$ & $3 \cdot 35 \pm 0 \cdot 28$ \\
\hline
\end{tabular}

${ }^{*} P<0 \cdot 05,{ }^{*} P<0 \cdot 01,{ }^{* * *} P<0 \cdot 001$, PS vs control.

as well as reduced adrenal $(P<0 \cdot 01)$ and pancreas $(P<0 \cdot 001)$ weight in males (Table 1$)$. Plasma glucose and CORT levels were also significantly reduced $(P<0 \cdot 05$ and $P<0.001$ respectively) in these foetuses (Table 1 ). However, plasma leptin levels were not affected by maternal stress (Table 1).

\section{Effect of PS on physiological parameters of aged male rats}

PS had no effect on body, adrenal, pancreas and fat depots weights (Table 2). Basal plasma CORT levels tended to increase in PS rats (Table 2) but statistical analysis was not significant $(P=0 \cdot 08)$. In contrast, plasma leptin levels, at rest, were reduced $(P<0 \cdot 05)$ in PS rats (Table 2$)$.

As shown in Fig. 1, the OGTT induced an increase of plasma glucose and insulin levels (time effect, glucose, $\mathrm{F}(2,28)=58.33, \quad P<0.001 ; \quad$ insulin, $\quad \mathrm{F}(2,28)=14 \cdot 78$, $P<0 \cdot 001)$. Aged PS rats had higher glucose levels than control rats at all investigated times (group effect, $\mathrm{F}(1,14)=4 \cdot 68, P<0 \cdot 05) \quad($ Fig. 1A). In contrast, insulin secretion after OGTT was similar between experimental groups (Fig. 1B).

Table 2 Effects of PS on body and organ weights and basal plasma CORT and leptin levels in 24-month-old male rats.

Data are means \pm S.E.M. $(n=7-8$ animals/group)

\begin{tabular}{|c|c|c|}
\hline & Control & PS \\
\hline Body weight (g) & $676 \cdot 14 \pm 17 \cdot 53$ & $647 \cdot 25 \pm 17 \cdot 02$ \\
\hline Adrenals (mg) & $77.93 \pm 6.92$ & $67 \cdot 21 \pm 4 \cdot 91$ \\
\hline Pancreas (g) & $1 \cdot 07 \pm 0 \cdot 07$ & $1.02 \pm 0.06$ \\
\hline Perirenal fat (g) & $6 \cdot 52 \pm 0 \cdot 72$ & $5 \cdot 44 \pm 0 \cdot 23$ \\
\hline Gonadal fat (g) & $4 \cdot 76 \pm 0 \cdot 56$ & $4 \cdot 38 \pm 0 \cdot 23$ \\
\hline Plasma CORT ( $\mu \mathrm{g} / \mathrm{dl})$ & $9 \cdot 29 \pm 2 \cdot 15$ & $16 \cdot 72 \pm 4 \cdot 34$ \\
\hline Plasma leptin (ng/ml) & $13 \cdot 55 \pm 0.99$ & $10 \cdot 28 \pm 0 \cdot 57^{*}$ \\
\hline
\end{tabular}

${ }^{*} P<0 \cdot 05$, PS vs control.
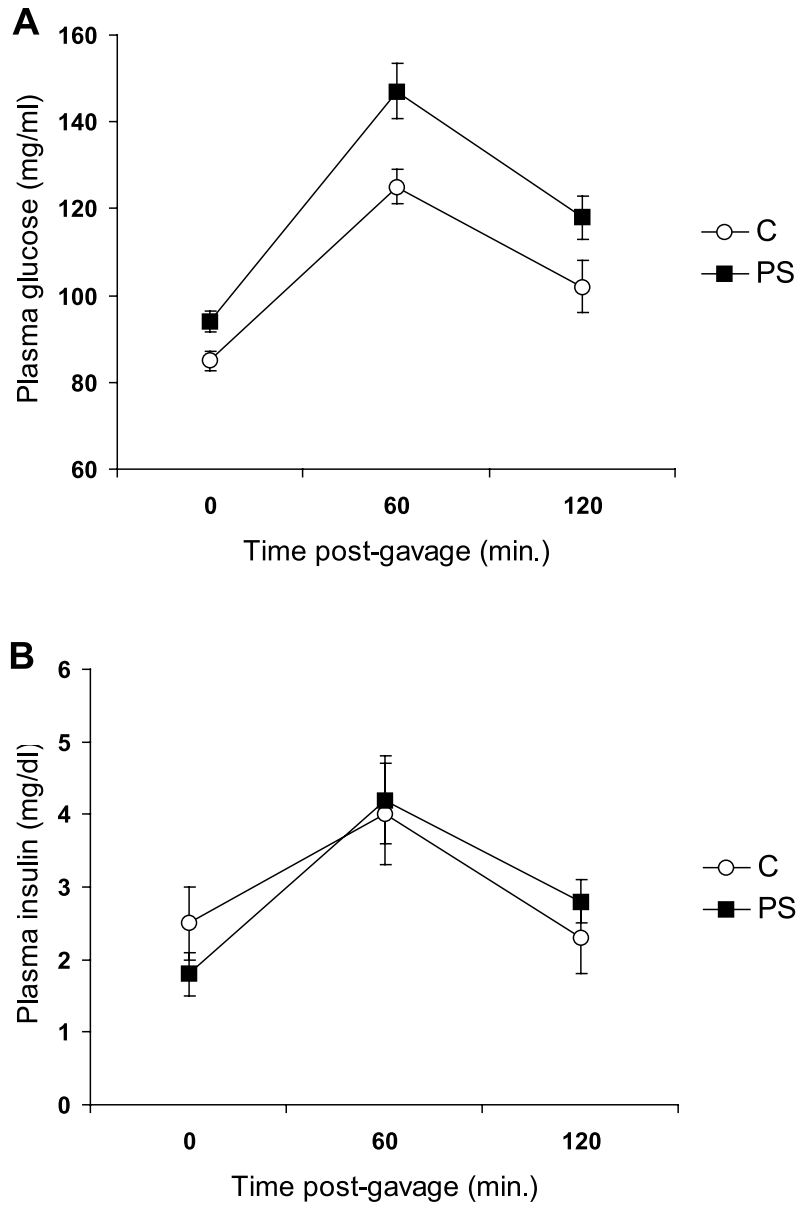

Figure 1 Effect of PS on plasma glucose (A) and insulin levels (B) during an OGTT in 24-month-old male rats. Values are means \pm S.E.M. from eight or nine animals/group.

Effect of PS on feeding behaviour of aged male rats

PS had no effect on the basal food intake in aged animals (control, $25 \cdot 7 \pm 1 \cdot 8 \mathrm{~g}$; PS, $25 \cdot 1 \pm 0 \cdot 6 \mathrm{~g}$ ). In contrast, after $24 \mathrm{~h}$ of fasting, the cumulative food intake over a period of $3 \mathrm{~h}$ was higher in PS rats than in controls (group effect, $\mathrm{F}(1,12)=14 \cdot 59, P<0 \cdot 01$; Fig. 2$)$. The time course of food consumption differed between control and PS rats. Indeed, PS rats continued to increase their food intake $2 \mathrm{~h}$ (NK post-hoc, $P<0 \cdot 001$ compared with the $1 \mathrm{~h}$ period) and $3 \mathrm{~h}$ (NK post-hoc, $P<0.05$ compared with the $2 \mathrm{~h}$ period) after food was placed in their home cage, whereas in controls there was no significant increase of food intake after the first hour.

\section{Discussion}

In the present study, we report that prenatal restraint stress induces a restriction of intrauterine growth in both male 


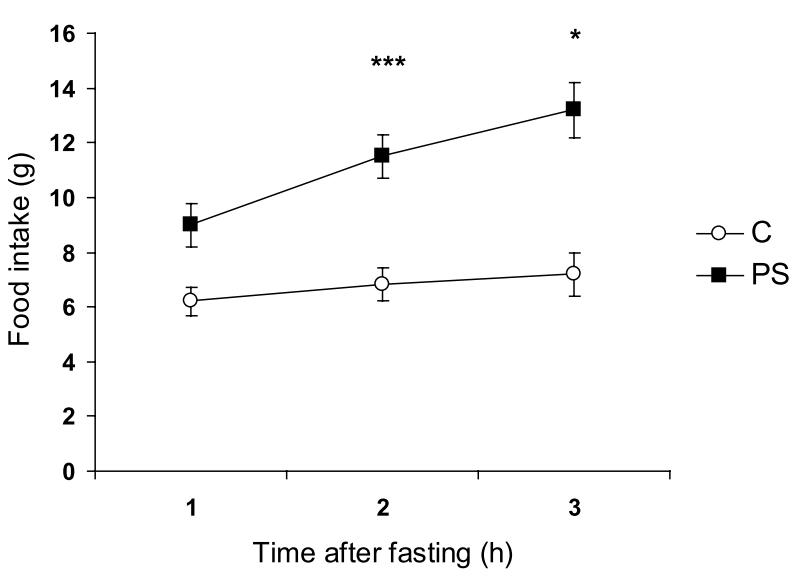

Figure 2 Effect of PS on cumulative food intake in 24-month-old male rats after $24 \mathrm{~h}$ of fasting. Values are means \pm S.E.M. from eight or nine animals/group. ${ }^{* * *} P<0 \cdot 001,2 \mathrm{~h}$ vs 1 h values; ${ }^{*} \mathrm{P}<0 \cdot 05,3 \mathrm{~h}$ vs $2 \mathrm{~h}$ values.

and female foetuses. Interestingly, we demonstrate for the first time in aged PS animals an increase of plasma glucose levels without a change in plasma insulin concentration after an OGTT procedure. Moreover, aged rats had reduced plasma leptin levels and showed an increase of food intake after a fasting period. These results suggest that PS could increase later vulnerability to metabolic diseases with ageing.

Our study indicates that maternal stress decreases foetal body weight at term, indicating a foetal growth restriction. Previous reports on the effects of PS on body weight are conflicting. Indeed, a reduced body weight of pups has been reported in some cases (Drago et al. 1999, Patin et al. 2002), whereas other studies have not revealed any differences (Power \& Moore 1986, Von Hoersten et al. 1993). These discrepancies could be a result of postnatal factors such as maternal milk yield. In our case, pups were removed by caesarean procedure, excluding the possibility of differences in milk secretion between control and stressed mothers (Lau 1992) or in milk intake in newborns.

Processes by which maternal stress affects pups development are unknown. However, numerous studies have shown that excessive glucocorticoids exposure in utero reduces birth weight and alters organ maturation in a variety of mammalian species, including primates and man (Reinisch et al. 1978, Novy \& Walsh 1983). Maternal hypersecretion of glucocorticoids as well as exogenous administration of CORT or dexamethasone has been reported to reduce both foetal adrenal growth and activity in parallel with a drastic reduction of both hypothalamic corticotrophin-releasing hormone content and plasma ACTH concentration (Dupouy et al. 1987, Lesage et al. 2001). Chronic restraint stress is known to increase CORT levels in pregnant dams (Barbazanges et al. 1996). We report here a reduction of CORT secretion and an atrophy of adrenal glands in the foetus at term. These modifications confirm the foetal glucocorticoid overexposure, since adrenal atrophy is a physiological adaptation in the foetus to attenuate high glucocorticoids levels. Our present results also indicate that maternal stress reduces both plasma glucose levels and pancreas weight in foetuses. In a previous study, we showed that the development of pancreatic islets and $\beta$-cells is extremely sensitive to glucocorticoids from both maternal or foetal adrenal glands (Blondeau et al. 2001). Indeed, inhibition of foetal steroid production drastically increases both islet number and $\beta$-cell mass, whereas overexposure to maternal glucocorticoids has opposite effects (Blondeau et al. 2001). The reduction of plasma glucose levels in foetuses from stressed mothers could result from numerous disturbances such as a reduced efficiency in placental (maternal-tofoetal) glucose transfer, or an increased foetal glucose metabolism.

When they were 24 months old, PS rats had no alterations in their body or organs weights. However, PS rats exhibited hyperglycaemia under basal conditions and after a glucose load, whereas insulinaemia was not affected. This is the first experimental proof suggesting that maternal stress could programme type 2 diabetes mellitus in aged offspring. These results extend other reports in the literature. Indeed, it has been shown that PS rats have high plasma glucose levels at the age of 5 months (Vallée et al. 1996). Present data suggest a persistent effect of PS on glycaemia. Administration of synthetic glucocorticoids during late gestation causes hyperglycaemia and glucose intolerance in adult rat offspring (Nyirenda et al. 1998). Moreover, inhibition of placental $11 \beta$-hydroxysteroid dehydrogenase type 2 , which protects the foetus from an excess of glucocorticoids of maternal origin, reduces birth weight and leads to impaired glucose tolerance in adult rats (Saegusa et al. 1999). So, our results reinforce the hypothesis that prenatal programming of glucose metabolism may be mediated by the glucocorticoid environment during foetal life. It was reported that early stress paradigms reduce the food intake in young adult rats (Vallée et al. 1996, Penke et al. 2001). We show that basal food intake was not altered in aged PS rats. We also report an increase of food intake after a fasting period in aged PS rats, suggesting an alteration of the feeding behaviour during stressful situations in these animals. PS reduces leptin secretion in aged offspring. Leptin is well documented to activate hypothalamic proopiomelanocortin/cocaineamphetamine-regulated transcript anorexigenic neurons and to inhibit NPY/AgRP orexigenic ones, resulting in a decreased food intake (Schwartz et al. 2000). So, it could be hypothesised that low leptin levels in PS rats could be involved in the increase of food intake. However, in PS rats this increase of food intake is only triggered after a fasting period. PS has been well described to provoke HPA axis hyperactivity in response to stress through life (Vallée et al. 1999). As CORT is implicated in the feeding behaviour after fasting (Castonguay 1991, Hamelink et al. 1994), it 
could be hypothesised that a differential corticosteroid response to the stress of fasting in PS rats could be implicated in the differences in food intake. The reduction of plasma leptin levels in aged PS rats, in spite of an unchanged weight of several adipose tissues, is quite surprising. However, an altered adipocyte metabolism may be involved since recent data demonstrate that prenatal dexamethasone exposure is associated with increased GR expression and attenuated fatty acid uptake in adult visceral adipose tissue (Cleasby et al. 2003).

Several data in humans suggest an early programming of adult diseases including an increased risk for developing a type 2 diabetes mellitus with ageing in subjects with a low body weight at birth. We demonstrate here that maternal stress induced an intrauterine growth restriction in rat foetuses and programmes a type 2 diabetes mellitus and eating disorders in aged offspring. These data support the concept of a prenatal programming of chronic adult diseases and demonstrate that stress during perinatal life may have a profound impact on health throughout life.

\section{Acknowledgements}

The authors gratefully acknowledge the assistance of Dr B Bréant and B Duchene (INSERM U457, Paris) for the insulin determination. We also thank Y Dodey for typing the manuscript and Prof. S Hawkins (University of Lille 1) for critical reading of the manuscript. We thank D Deschamps and S Lefevre for animal care.

\section{Funding}

This work was supported by the University of Lille 1 and the Ministère de l'Education Nationale, de l'Enseignement Supérieur et de la Recherche. There are no conflicts of interest in this study.

\section{References}

Barbazanges A, Piazza PV, Le Moal M \& Maccari S 1996 Maternal glucocorticoid secretion mediates long-term effects of prenatal stress. Journal of Neuroscience 16 3943-3949.

Barker DJP 1998 Mothers, Babies and Health in Later Life, edn 2. Edinburgh: Churchill Livingstone.

Barker DJP \& Osmond C 1986 Infant mortality, childhood nutrition, and ischaemic heart diseases in England and Wales. Lancet 1 1077-1081.

Blondeau B, Lesage J, Czernichow P, Dupouy JP \& Bréant B 2001 Glucocorticoids impair fetal $\beta$-cell development in rats. American Journal of Physiology. Endocrinology and Metabolism 281 592-599.

Castonguay TW 1991 Glucocorticoids as modulators in the control of feeding. Brain Research Bulletin 27 423-428.

Cleasby ME, Kelly PA, Walker BR \& Seckl JR 2003 Programming of rat muscle and fat metabolism by in utero overexposure to glucocorticoids. Endocrinology 144 999-1007.
Drago F, Di Leo F \& Giardina L 1999 Prenatal stress induces body weight deficit and behavioural alterations in rats: the effect of diazepam. European Neuropsychopharmacology 9 239-245.

Dupouy JP, Chatelain A, Boudouresque F, Conte-Devolx B \& Oliver C 1987 Effects of chronic maternal dexamethasone treatment on the hormones of the hypothalamo-pituitary-adrenal axis in the rat fetus. Biology of the Neonate 52 216-222.

Hamelink CR, Currie PJ, Chambers JW, Castonguay TW \& Coscina DV 1994 Corticosterone-responsive and -unresponsive metabolic characteristics of adrenalectomized rats. American Journal of Physiology 267 799-804.

Holness MJ, Langdown ML \& Sugden MC 2000 Early-life programming of susceptibility to dysregulation of glucose metabolism and the development of type 2 diabetes mellitus. Biochemical Journal 349 657-665.

Koehl M, Darnaudery M, Dulluc J, Van Reeth O, Le Moal M \& Maccari S 1999 Prenatal stress alters circadian activity of hypothalamo-pituitary-adrenal axis and hippocampal corticosteroid receptors in adult rats of both gender. Journal of Neurobiology $\mathbf{4 0}$ 302-315.

Lau C 1992 Effects of various stressors on milk release in the rat. Physiology and Behavior 51 1157-1163.

Lesage J, Blondeau B, Grino M, Bréant B \& Dupouy JP 2001 Maternal undernutrition during late gestation induces fetal overexposure to glucocorticoids and disturbs the hypothalamopituitary-adrenal axis in the newborn rat. Endocrinology 142 1692-1702.

Lesage J, Hahn D, Léonhardt M, Blondeau B \& Dupouy JP 2002 Maternal undernutrition during late gestation-induced intrauterine growth restriction in the rat is associated with impaired placental GLUT3 expression, but does not correlate with endogenous corticosterone levels. Journal of Endocrinology 174 37-43.

Maccari S, Piazza PV, Kabbaj M, Barbazanges A, Simon H \& Le Moal M 1995 Adoption reverses the long-term impairment in glucocorticoid feedback induced by prenatal stress. Journal of Neuroscience 15 110-116.

Maccari S, Darnaudery M, Morley-Fletcher S, Zuena AR, Linque C \& Van Reeth O 2003 Prenatal stress and long-term consequences: implications of glucocorticoid hormones. Neuroscience and Biobehavioral Reviews 27 119-127.

Nathanielsz PW \& Thornburg KL 2003 Fetal programming: from gene to functional systems - an overview. Journal of Physiology 547 3-4.

Novy MJ \& Walsh SW 1983 Dexamethasone and estradiol treatment in pregnant rhesus macaques: effects on gestation length, maternal plasma hormones and fetal growth. American Journal of Obstetrics and Gynecology 145 920-930.

Nyirenda MJ, Lindsay RS, Kenyon CJ, Burchell A \& Seckl JR 1998 Glucocorticoid exposure in late gestation permanently programs rat hepatic PEPCK and GR expression and causes glucose intolerance in adult offspring. Journal of Clinical Investigation 101 2174-2181.

Patin V, Lordi B, Vincent A, Thoumas JL, Vaudry H \& Caston J 2002 Effects of prenatal stress on maternal behavior in the rat. Developmental Brain Research 139 1-8.

Penke Z, Felszeghy K, Fernette B, Sage D, Nyakas C \& Burlet A 2001 Postnatal maternal deprivation produces long-lasting modifications of the stress response, feeding and stress-related behaviour in the rat. European Journal of Neuroscience 14 747-755.

Power KL \& Moore CL 1986 Prenatal stress eliminates differential maternal attention to male offspring in Norway rats. Physiology and Behavior 38 667-671.

Reinisch JM, Simon NG, Karwo WG \& Gandelman R 1978 Prenatal exposure to prednisone in humans and animals retards intra-uterine growth. Science 202 436-438.

Saegusa H, Nakagawa Y, Liu YJ \& Ohzeki T 1999 Influence of placental 11 beta-hydroxysteroid dehydrogenase (11 beta-HSD) inhibition on glucose metabolism and 11 beta-HSD regulation in adult offspring of rats. Metabolism 48 1584-1588. 
Schwartz MW, Woods SC, Porte D, Seeley RJ \& Baskin DG 2000 Central nervous system control of food intake. Nature 404 661-671.

Seckl JR 2001 Glucocorticoid programming of the fetus; adult phenotypes and molecular mechanisms. Molecular and Cellular Endocrinology 185 61-71.

Vallée M, Mayo W, Maccari S, Le Moal M \& Simon H 1996 Long-term effects of prenatal stress and handling on metabolic parameters: relationship to corticosterone secretion response. Brain Research 712 287-292.

Vallée M, Maccari S, Dellu F, Simon H, Le Moal M \& Mayo W 1999 Long-term effects of prenatal stress and postnatal handling on age-related glucocorticoid secretion and cognitive performance: a longitudinal study in the rat. European Journal of Neuroscience $\mathbf{1 1}$ 2906-2916.

Von Hoersten S, Dimitrijevic M, Markovic BM \& Jankovic BD 1993 Effect of early experience on behavior and immune response in the rat. Physiology and Behavior 54 931-940.

Received in final form 29 January 2004

Accepted 6 February 2004

Made available online as an

Accepted Preprint 8 March 2004 